\title{
Representações sociais a partir de um grupo de WhatsApp: contrapontos entre sociedade em rede de Castells e vida líquida de \\ Bauman
}

Este artigo procura evidenciar pressupostos do conceito de Sociedade em Rede levantado por Castells (1999) e Vida Líquida proposto por Bauman (2007), investigado a partir do conceito de Representações Sociais e através de um grupo específico de alimentação saudável em uma Rede Social - WhatsApp. Parte-se do pressuposto que Castells (1999) amplia a ideia de que a sociedade está organizada em rede e vive-se hibridamente em presença física e presença virtual. Para Bauman (2007), a vida líquida dos laços sociais facilmente desfeitos no ciberespaço. Analisadas as Representações Sociais identificadas durante este estudo, foi possível elucidar um entendimento sobre a realidade dos membros do grupo a partir das seguintes categorias: Qualidade de Vida e Prática ou Hábitos Alimentares. Contudo, não subestimando as demais, pode-se dizer que essas Representações Sociais configuram o principal sistema de valores e de práticas de alimentação saudável para o grupo estudado.

Palavras-chave: Sociedade em Rede; Vida Líquida; Redes Sociais.

\section{Social representations from a WhatsApp group: considerations between in Castells society network and Bauman Liquid Life}

\begin{abstract}
This article aims at evidencing assumptions of the concept of Network Society raised by Castells (1999) and Liquid Life proposed by Bauman (2007), researched from the concept of Social Representations and through a specific group of healthy eating in a Social Network - WhatsApp. It is assumed that Castells (1999) expands the idea that society is organized in a network and lives hybridly in physical and virtual presence. While for Bauman (2007), the liquid life of social bounds easily broken in cyberspace. It has been analyzed the Social Representations identified during this study, it was possible to elucidate an understanding of the reality of the group members from the following categories: Quality of Life and Practice or Eating Habits. However, it may not underestimate the others, it can be said that these Social Representations constitute the main system of values and healthy eating practices for the studied group.
\end{abstract}

Keywords: Network Society; Liquid Life; Social Networks.

Topic: Comportamento Organizacional

Reviewed anonymously in the process of blind peer.
Received: 15/11/2019

Approved: $21 / 03 / 2020$
Bruno Silvestre Silva de Souza

Instituto Federal de Alagoas, Brasil

http://lattes.cnpq.br/8296982141032021

brunosilvestre@yahoo.com.br

Daniel Felipe Victor Martins

Universidade Federal Rural de Pernambuco, Brasil

http://lattes.cnpq.br/6868005868270518

dfvicmar@gmail.com

André Felipe de Albuquerque Fell (iD

Universidade Federal de Pernambuco, Brasil

http://lattes.cnpq.br/1601616623669281

http://orcid.org/0000-0002-3179-2595

highland97@hotmail.com
Referencing this:

SOUZA, B. S. S.; MARTINS, D. F. V.; FELL, A. F. A.. Representações sociais a partir de um grupo de WhatsApp: contrapontos entre sociedade em rede de Castells e vida líquida de Bauman. Business Journal, v.2, n.1, p.1-11, 2020. DOI: http://doi.org/10.6008/CBPC26746433.2019.001.0001 


\section{INTRODUÇÃO}

O entendimento do papel do Grupo de WhatsApp nomeado de 'Por Uma Vida Com Mais Vida' na constituição das Representações Sociais (MOSCOVICI, 2012), trata nas suas interações sobre questões que envolvem a alimentação saudável ao passo em que retoma a noção de sistemas de pensamento e seus universos: reificado e consensual. $\mathrm{O}$ universo reificado manifesta saberes com objetividade e rigor lógico e metodológico - é o universo das ciências. O universo consensual expressa o senso comum e suas teorias de resposta aos problemas do real - é o universo das representações sociais que circundam o cotidiano.

Fazendo a ponte entre eles, destaca-se o grupo aqui estudado, por seu intermédio, a socialização dos participantes que possibilita interpretar vivências e torná-las comuns. Assim, os conhecimentos científicos são moldados a um contexto social e ganham nova significação, isto porque ambos universos se interrelacionam podendo dar forma à realidade.

Castells (1999) vai ampliar essa ideia ao afirmar que a sociedade está organizada em rede. Em todos os campos da vida social, vive-se hibridamente em presença física e presença virtual, possíveis e impulsionadas pelas novas tecnologias que transcendem o tempo e o espaço. A sociabilidade se assenta nas potencialidades de comunicação que a Internet oferece para a partilha de sentimentos, ideias, conhecimentos, informações e conceitos.

Nessa sociedade, os grupos de WhatsApp são como uma inteligência coletiva, não artificial, mas de alta interação, em que o sentido é formado pela complementação das informações na mente da audiência, sem a ligação física entre as partes. A informação pode ser democratizada por seu fluxo contínuo e o conhecimento não é mais uma propriedade intelectual, mas sim algo que interage e é mutável. Tal fluidez poderia resultar em uma frouxura, ou mais adequadamente em uma liquidez. Porém, ao contrário do que afirma Bauman (2007), a vida líquida dos laços sociais facilmente desfeitos no ciberespaço, não se configura no grupo estudado. Se a sociedade atual é líquido-moderna, pois seus membros agem em condições que mudam num intervalo de tempo mais curto do que o necessário para a consolidação das formas de agir em hábitos e rotinas, o grupo 'Por Uma Vida Com Mais Vida' tenta criar laços fortes e duráveis, consequentemente difíceis de serem desfeitos.

Na verdade, o que está pesquisa ressalta é justamente o oposto à modernização líquida. Através da tecnologia existe algo maior do que o líquido quando aparece na sociedade a busca por uma solidificação das relações, como no grupo 'Por Uma Vida Com Mais Vida'. Rompem-se os muros do universo reificado dos conhecimentos científicos rumo ao universo consensual das conexões ampliadas e do aumento da circulação da informação. Isso faz a percepção das pessoas envolvidas aumentar no tocante à alimentação saudável, que passa a ter também uma função pedagógica (MARTINS et al., 2007).

A partir do exposto, interessa saber como a alimentação é considerada saudável no ponto de vista dos indivíduos que participam de uma rede social cujo objetivo é disseminar informações e criar conscientização para sua adoção. Atuando na fronteira entre senso comum e conhecimento científico, levanta-se, portanto, uma questão de pesquisa: quais as possíveis características das Representações Sociais 
de consumo de alimentação saudável dos membros do grupo de WhatsApp 'Por Uma Vida Com Mais Vida'?

Para responder tal questão de pesquisa, foram propostos os respectivos objetivos geral e específicos:

Objetivos Geral: Evidenciar pressupostos do conceito de Sociedade em Rede levantado por Castells (1999) e Vida Líquida proposto por Bauman (2007), investigado a partir do conceito de Representações Sociais a partir de um Grupo específico em uma Rede Social - WhatsApp.

Objetivos Específicos: a) identificar as Representações Sociais de alimentação saudável entre os integrantes do grupo; b) verificar como a participação nesse grupo social específico tem contribuído para a constituição das Representações Sociais do que vem a ser alimentação saudável; c) analisar as Representações Sociais do grupo WhatsApp a partir do conceito de Sociedade em Rede levantado por Castells (1999) e de Vida Líquida proposto por Bauman (2007).

Portanto, espera-se alcançar tais objetivos e encontrar respostas sobre o valor do grupo, justificado, sobretudo, a partir da necessidade do reconhecimento crescente do caráter parcial do conhecimento científico, bem como da necessidade de encontrar possíveis diálogos sobre tal conhecimento com base nas Representações Sociais.

\section{REVISÃO TEÓRICA}

\section{Teoria das Representações Sociais}

A Teoria das Representações Sociais nasceu do questionamento de Moscovici (2012), sobre como o conhecimento científico transformava-se em conhecimento comum. A essa indagação ele forneceu respostas que permitem lidar com as lutas e polêmicas culturais que emergem do contato da sociedade com uma nova ideia ou teoria.

Historicamente, a teoria baseia-se no pensamento de Durkheim sobre as representações coletivas e a necessidade de reconhecimento da oposição entre individual e coletivo, mas dele se difere pela concepção de que as relações entre sociedade e cultura são interdependentes, contraditórias e mutáveis e não estáticas, como defendia Durkheim. Assim expõem Costa et al. (1999):

[...] o substrato da representação individual era a consciência própria de cada um, sendo, portanto, subjetiva, flutuante e perigosa à ordem social. Por outro lado, o substrato da representação coletiva era a sociedade em sua totalidade e, por isso, seria impessoal e ao mesmo tempo permanente, garantindo, assim, a ligação necessária entre os indivíduos e, consequentemente, a harmonia da sociedade.

Moscovici (2012) suplanta essas questões ao enfatizar a interação dialética entre sociologia e antropologia, confirmando a Teoria das Representações Sociais como uma especificidade da Psicologia Social. Conceitualmente, as Representações Sociais são uma das vias de apreensão do mundo concreto por meio da transformação do conhecimento indireto em direto na apropriação do mundo exterior (MOSCOVICl, 2012).

Jodelet (1989) considera as Representações Sociais uma forma de conhecimento socialmente elaborada e partilhada, de objetivo prático, que contribui para a construção da realidade comum a um conjunto social. Utilizado na vida cotidiana, esse conhecimento cria um senso comum. A teoria atua para 
valorizar o conhecimento construído socialmente e o torna elemento importante de investigação científica para transformação social no seu processo de formação. O senso comum alcança o status de objeto de estudo legítimo pelo próprio reconhecimento da existência das Representações, uma vez que indica práticas sociais a respeito de diversos assuntos.

\section{Processo de Formação das Representações Sociais}

Moscovici (2012) reconhece que as representações sociais realizam uma reestruturação cognitiva com o movimento mental de tornar familiar o não familiar. Elas podem, por exemplo, servir para explicar ou justificar a identidade do indivíduo nas suas razões para inserir-se num grupo ou dele não fazer parte. Essa assimilação ocorre por meio de dois processos: objetivação e ancoragem que representam um duplo mecanismo de natureza psicológica e social.

A objetivação é o momento em que o abstrato se transforma em concreto. É a organização das percepções e os julgamentos dos indivíduos em uma realidade socialmente construída, cristalizadora das ideias, tornando-as objetivas. A chamada face figurativa de materialização do conhecimento (MOSCOVICl, 2012). O processo traz o que até então não existia ao mundo do conhecido e desenvolve-se em três fases, como apresentadas por Jodelet (1989):

1. Seleção e Contextualização: as informações sobre o objeto passam por uma seleção com base em critérios culturais. As experiências e conhecimentos do grupo permitem haver uma construção seletiva da realidade;

2. Formação de um Núcleo Figurativo: esses elementos são organizados num padrão de relações estruturadas. $O$ indivíduo recorre a informações e dados que já possui para compreender aquilo que é novo;

3. Naturalização dos Elementos do Núcleo Figurativo: as informações alcançadas e suas respectivas relações formam-se como categorias naturais, caracterizando sua materialidade. $O$ abstrato torna-se concreto, quase tangível e o conceito, cristalizado, passa a ser considerado como elemento da própria realidade.

A objetivação, contudo, não garante a inserção desse conhecimento. Para isso é necessária a atuação dialética da ancoragem (JODELET, 1989). A ancoragem consiste em integrar cognitivamente o objeto representado a um sistema de pensamento social preexistente. As imagens dadas pela objetivação são assimiladas e sedimentam-se num registro simbólico de nomeação do que não tinha nome. É o processo de familiarização do novo e de sua transformação em um conhecimento hábil a influenciar outras pessoas.

Pela classificação do que é inclassificável, pelo fato de dar um nome ao que não tinha nome, nós somos capazes de imaginá-lo, de representá-lo. De fato, a representação é, fundamentalmente, um sistema de classificação e de denotação, de alocação de categorias e nomes. (MOSCOVICl, 2012)

A ancoragem serve para a instrumentalização do saber com o valor funcional de permitir ver a objetivação. Assim, objetivação e ancoragem definem a forma pela qual as novas informações são percebidas, transformadas, integradas e moduladas numa rede de significações construídas a partir das relações sociais que interpretam o objeto. Todo esse processo envolve juízo de valores na classificação e categorização do novo numa cadeia de significações, em que 'o antigo e o atual são confrontados' (JOVCHELOVITCH, 2003). 
Ressalta-se que objetivação e ancoragem não ocorrem em momentos distintos. Antes, desenvolvemse concomitantemente numa inter-relação de construção de sentidos. A objetivação, direcionada para fora ou para outros, elabora conceitos e imagens para reproduzi-los no mundo exterior. A ancoragem permeia motivos e tendências toda vez que o participante é chamado a olhar para dentro de si e do que armazena em sua memória em movimento (MOSCOVICl, 2012). Ancoragem e objetivação são, pois, maneiras de lidar com a memória.

As Representações Sociais ampliam seu leque de atuação ao também apresentar a capacidade de ser 'um guia para as ações sociais' (ABRIC, 2000) ao mesmo tempo em que a Representação é influenciada pelo meio no qual se cristalizou, ela o influencia, porque se torna ponto de partida de uma nova interpretação da realidade ou visão do mundo.

\section{Universos de Pensamento}

No processo de formação das Representações Sociais, a realidade é dividida em sistemas de pensamentos distintos: os universos reificado e consensual, que permitem entender os conceitos de familiar e não familiar. Para Moscovici (2012), o universo reificado manifesta saberes e conhecimentos com objetividade, sendo o universo das ciências. $O$ universo consensual, por sua vez, expressa o senso comum e suas teorias de resposta aos problemas do real, sendo o universo do senso comum. Ambos se interrelacionam dando forma à realidade.

Moscovici (2012) afirma que "a representação toma o lugar da ciência e, por outro, a constitui (ou reconstitui) a partir das relações sociais envolvidas". Os conhecimentos científicos são moldados a um determinado contexto social e ganham nova roupagem com significação própria. Dessa forma, o conhecimento científico pode tornar-se elemento da própria cultura transformado em conhecimento comum. Moscovici (2012) defende que cada universo apresenta três dimensões:

1. Informação (dimensão ou conceito): organização dos conhecimentos que um grupo possui acerca de um objeto;

2. Campo de Representação: remete à ideia de imagem, modelo, a um aspecto preciso do objeto social;

3. Atitude: destaca a orientação global em relação ao objeto da representação social e ocorre quando o indivíduo representa algo unicamente após ter adotado uma posição e em função da posição tomada. No caso do grupo estudado, é o que ocorre em todos os questionamentos sobre influências, mudanças e conscientização após adesão.

\section{Funções das Representações Sociais}

Um dos objetivos primordiais das Representações Sociais é tornar familiar algo até então desconhecido. Nesse percurso podem ser identificadas quatro funções essenciais, conforme Abric (2000):

1. Função de Saber: permite compreender e explicar determinada realidade, em consonância com sistema cognitivo e o universo de valores e crenças do indivíduo. Facilita a comunicação e a difusão do saber ingênuo;

2. Função Identitária: proteção da especificidade dos grupos, na medida em que situa os indivíduos ou grupos no campo social, definindo a identidade e exercendo papel de suma importância no controle social; 
3. Função de Orientação: opera como seleção e filtro de informações e atua como guia de comportamentos e práticas sociais. Direciona e adequa quando intervém na finalidade da situação e no tipo de atitude cognitiva a ser adotada pelos sujeitos sociais. Revela sua natureza prescritiva na antecipação das ações;

4. Função Justificadora de Condutas: atua a posteriori para possibilitar explicar e justificar comportamentos e tomadas de posição e decisão dos grupos e indivíduos numa ação ou em relação aos seus parceiros;

Por fim, as Representações Sociais possuem grande importância para as práticas sociais, pois contribuem e influenciam a construção da própria realidade. Como salienta Moscovici (2012):

As representações que se formam na sociedade, têm repercussão direta em seu comportamento, atitudes e modos de agir, pois formam estruturas individuais de conhecimentos que informam e orientam os membros de um grupo social, em determinado tempo e espaço.

As representações sociais foram escolhidas pela sua importância entre escolher para utilizar Ancoragem e Objetivação e a importância para observar e analisar o tema proposto.

\section{METODOLOGIA}

O presente estudo se constituiu em caso único de natureza qualitativa. A natureza de estudo de caso surgiu de sua característica circunscrita a um grupo organizado por meio de uma rede social com o intuito de disseminar informações e criar conscientização para adoção de práticas de alimentação saudável. Tal situação permite seu caráter de profundidade e detalhamento, como assinala Vergara (2005). Na atualidade, é o delineamento mais adequado para investigar fenômenos contemporâneos no seu contexto real (GIL, 2008).

As pesquisas que utilizam a abordagem qualitativa possuem a facilidade de poder descrever a complexidade de determinada hipótese ou problema, analisar a interação de certas variáveis, compreender e classificar processos dinâmicos experimentados por grupos sociais, apresentar contribuições no processo de mudança, criar ou formar opiniões sobre determinado grupo e permitir, em maior grau de profundidade, a interpretação das particularidades dos comportamentos ou atitudes dos indivíduos.

Quanto aos fins, a pesquisa também foi considerada explicativa, pois está centrada na preocupação de identificar fatores determinantes ou contributivos ao desencadeamento dos fenômenos, explicar a razão do fato ou fenômeno social e justificar motivos. Os procedimentos básicos são: registrar, classificar, identificar e aprofundar a análise (VERGARA, 2005).

A coleta de dados foi realizada por meio de interação online, junto aos membros do grupo em análise. O trabalho tem um determinado caráter de inovação por se tratar de uma investigação científica no aplicativo WhatsApp como afirmado anteriormente. Como afirmam Fontelles et al. (2009), a pesquisa científica não precisa ser totalmente inédita, porém em nada se justifica repetir estudos cujos resultados já estão bem estabelecidos pela comunidade científica.

\section{RESULTADOS E DISCUSSÃO}

O entendimento do papel do Grupo 'Por Uma Vida Com Mais Vida' na constituição de 
Representações Sociais sobre alimentação saudável retoma a noção de sistemas de pensamento e seus universos: consensual e reificado.

Definidos os universos de pensamento, Oliveira et al. (2003) concluem que o não familiar é constituído no universo reificado das ciências e, com o auxílio de divulgadores científicos é transferido ao universo consensual, do dia-a-dia. Por isso, a ocorrência desse processo de troca de mensagens em meio virtual responde a uma condição atual de comunicação.

Castells (1999) amplia essa ideia ao afirmar que a sociedade está organizada em rede. Em todos os campos da vida social, vive-se hibridamente em presença física e presença virtual, possíveis e impulsionadas pelas novas tecnologias que transcendem o tempo e o espaço. A sociabilidade se assenta nas potencialidades de comunicação que a Internet oferece para a partilha de sentimentos, ideias, conhecimentos, informações e conceitos. Nessa sociedade, os grupos de WhatsApp são como uma inteligência coletiva, não artificial, de alta participação (ou interação), em que o sentido é formado pela complementação das informações na mente da audiência, sem a ligação física entre as partes.

A visão de Bauman (2007) se inscreve no terreno do tecnopólio, processo que levou a tecnologia a ser o soberano e a sociedade humana a ser o servo. Contudo, essa de determinismo social, ou seja, imperativo ou determinismo tecnológico versus a construção social da tecnologia é anterior a Bauman. Na obra Tecnopólio: A Rendição da Cultura à Tecnologia, de 1994, Neil Postman alertava sobre essa situação. Quase duas décadas depois Silva et al. (2013) compuseram uma resenha sobre a obra de Postman e afirmaram que o tecnopólio passou a ser, então, um estado de cultura, envolto em seus próprios dogmas e misticismos, impondo o rumo e o ritmo de vida às sociedades.

Na verdade, o que está pesquisa ressalta é justamente o oposto à modernização líquida. Através da tecnologia existe algo maior do que o líquido quando aparece na sociedade a busca por uma solidificação das relações, como no grupo Por Uma Vida Com Mais Vida. Como características particulares, o grupo 'Por uma Vida Com Mais Vida' está organizado numa rede social de troca de mensagens WhatsApp em que as pessoas apresentam dúvidas, respostas e informações. Ele é composto por 100 membros e dois moderadores e está direcionado a público específico que sabe que está escrevendo a memória não só do grupo, mas da sua própria percepção do que é alimentação saudável no momento em que ela está sendo construída. As formas de transmissão são postagens de textos e vídeos, áudios gravados e links sobre o tema.

O grupo é uma ferramenta do conhecimento e ao mesmo tempo uma produção colaborativa. Claro está que esse conhecimento tende a ser construído de forma ética, daí as regras de boa convivência. $O$ grupo Por Uma Vida Com Mais Vida afirma que retrabalha e comunica práticas sociais de conhecimentos não científicos sobre alimentação saudável e, por isso, pode-se afirmar que as regras de boa convivência organizam sua forma de pensar e agir:

1. O áudio deve ser ferramenta da moderadora para explicar os assuntos mais complexos, por ser mais rápido e claro. Os demais participantes devem usar a escrita para não sobrecarregar os celulares dos demais participantes;

2. Mensagens de bom dia devem ser usadas com cautela, sempre pensando em deixar os celulares mais livres para receber as informações; 
3. O grupo se chama Por uma Vida com mais Vida. Assim, assuntos como esporte, religião, política, NÃO devem ser compartilhados. No entanto, com assuntos de cunho espiritual (NÃO RELIGIOSO) não haverá problema, pois se entende que a espiritualidade é fundamental em uma vida com mais vida!;

4. Quando alguém for expor algum vídeo ou link, colocar do que se trata para que seja fácil localizar posteriormente;

5. NÃO usar o grupo para falar de assuntos que não seja do interesse coletivo;

6. A comunicação de compras de produtos deve ser tratada em privado com o facilitador específico;

7. Tentar não repetir posts, principalmente se for da mesma pessoa;

8. Ter paciência é fundamental para um bom convívio e uma Vida Com Mais Vida!

Esse diálogo pode modificar a posição dos indivíduos sobre o entendimento do que é comida e ampliá-lo para uma ideia de realização de todo o conjunto de atos voluntários e conscientes para a preparação das refeições e ingestão de alimentos, estando intimamente relacionada com o ambiente sociocultural e econômico a que pertencem (BOURDIEU, 2007).

Assim, ante o objetivo de analisar as representações sociais de alimentação saudável dos integrantes do grupo organizado em rede social - WhatsApp - 'Por uma Vida Com Mais Vida', este trabalho deparou-se com a tarefa de demonstrar, por meio da Teoria das Representações Sociais, as vias de apreensão do mundo concreto da alimentação saudável num contexto social de comunicação mediada.

Em se tratando de alimentação saudável, campo de embates entre correntes de pensamento e ação muitas vezes antagônicas, além dos discursos científicos, da esfera pública e do mercado de produtos de consumo, optar pelas Representações Sociais constitui uma opção para descrição e explicação dos fenômenos sociais ao reproduzir pensamentos e comportamentos comuns a um grupo de indivíduos. Sempre lembrando que o senso comum é objeto de estudo tão legítimo quanto o conhecimento científico.

Como as Representações Sociais resultam da própria interação social em determinado tempo e espaço, para alcançar o objetivo, conjugou-se a análise de duas principais questões: o que representava alimentação saudável para os respondentes e de que forma a participação no grupo contribuiu para desenvolver a compreensão sobre o que é alimentação saudável. Desse conjunto de respostas emergiram categorias de Representações Sociais.

Quanto ao que representa alimentação saudável, é possível apontar Qualidade de Vida como a Representação associada a bom-humor, disposição, bem-estar, ausência de doenças, equilíbrio, longevidade e menor consumo de remédios. Saudabilidade é uma Representação que ganha forma com os elementos vitalidade, alimentação sem vícios, ingestão de alimentos saudáveis, beleza, e manutenção da saúde. Juntamente com a Qualidade Vida, pode-se forma um Eixo Temático designado de Saúde e Cuidados de Si.

Na direção à adoção de uma corrente alimentar, o Vegetarianismo também é uma Representação que corresponde ao consumo de alimentos orgânicos e integrais. Associa-se também à ingestão de frutas, folhas, brotos, sementes, grãos, castanhas, raízes, sucos e água natural. De maneira negativa, a abolição de industrializados, de ingestão de refrigerantes, doces, enlatados, açúcar, frituras, carne e gorduras animal, hidrogenada e trans. 
O Crudivorismo especifica esse consumo ao colocar a comida crua como ponto central. Os alimentos recebem nessa Representação o status de vivos e são, muitas vezes, germinados. Para além do Vegetarianismo estrito existe o Semivegetarianismo, que se divide em Ovolactovegetarisnismo, aquele em que além dos vegetais se utilizam aves, peixes, ovos, leite e derivados e Lactovegetarianismo, em que os ovos são abolidos.

Preparação adequada dos alimentos é uma Representação materializada nos elementos quantidade correta, melhora da digestibilidade, menor cozimento, escolha consciente dos alimentos e boa nutrição. Alimentação equilibrada ou balanceada reúne os elementos anteriormente citados numa Representação menos extremada, mas que valoriza o gasto calórico suficiente à realização das atividades, a não sobrecarga do sistema metabólico, o afastamento dos agrotóxicos, o horário correto para se alimentar e a manutenção da saúde. O equilíbrio também é alcançado pela ingestão frugívora e pelo consumo de fibras.

Reunidas, essas Representações formam um Eixo Temático Natural versus Artificial que está na raiz dos embates sobre alimentação saudável e, não surpreendentemente, é uma ideia mencionada repetidamente nas respostas. A Representação Proximidade Com a Natureza propõe um comer mais próximo à forma natural dos alimentos. Essa preocupação baseia-se na possibilidade de obtenção de regeneração, corpo saudável e vitalidade trazidos pelos alimentos minimamente processados. Dela também faz parte o ativismo alimentar. A conclusão é de que essa Representação significa ter um estilo de vida mais perto da natureza dentro de uma filosofia própria.

Hábitos Mais Saudáveis completam as Representações de alimentação saudável como exercício da possibilidade prática de elevação da autoestima e da espiritualidade. Vidas física e emocional misturam-se nessa Representação para exprimir o bem-estar e a certeza de fazer o melhor para si e para a família. A alimentação saudável é vista como aquela que nutre o corpo e a alma. Proximidade com a Natureza e Hábitos Mais Saudáveis formam o Eixo Temático Espiritualidade.

Quanto à contribuição do grupo no desenvolvimento da compreensão sobre o que é alimentação saudável, Qualidade de Vida reaparece, dessa vez, matizada pelos cuidados com a saúde e a melhoria de hábitos, por meio de trocas de experiência. Em ambas as situações de sua ocorrência, a multiplicidade de elementos revela o caráter psicológico e social característico das Representações Sociais. Pode-se colocá-la também no Eixo Temático Saúde e Cuidados de Si.

A Representação prevalente, contudo, é a Aprendizagem, entendida como troca de informações, o que era de se esperar de um grupo baseado no uso de uma ferramenta com esse mesmo propósito. Ainda assim, demonstra de que maneira as Representações preenchem o espaço entre o familiar e o não familiar, o sabido e o por saber.

$\mathrm{Na}$ mesma linha, a Representação Conhecimentos Específicos, terciária, reúne ampliação de conhecimentos, busca ativa de conhecimentos, conhecimento do próprio organismo, conhecimento que faz bem para a própria vida, otimização do conhecimento e informações objetivas e reforça o papel da Aprendizagem. A elas une-se a representação Uso da Mídia que atualiza o conhecimento por meio de recursos audiovisuais. Junta, essas três Representações formam o Eixo Temático Informação Para Formação 
da Consciência. Em outras palavras, em alguns casos quanto mais informação mais conscientização.

A ideia de trazer a informação à realidade concreta reaparece com a Representação Prática ou Resultados Práticos, evidenciada pelo desenvolvimento da capacidade de distinção entre alimentos saudáveis e industrializados, de planejamento alimentar, incorporação de hábitos mais saudáveis, incentivo aos exercícios físicos, avaliação de mudanças físicas, perda de peso (massa) e percepção de saudabilidade. Esse é o caso de superação da lacuna entre a busca pela mudança e a realidade da prática por meio das Representações Sociais. Em termos temáticos, essa Representação forma seu próprio eixo no contexto de desenvolvimento da conscientização sobre alimentação saudável.

A Representação Motivação, fator de continuidade e força de vontade para mudança de hábitos pode ser conjugada à Espiritualidade como adoção de visão positiva e holística. Reunidas à Representação Informação Afetiva formam o Eixo Temático Emocionalidade na capacidade dos indivíduos de reagirem a sentimentos e emoções.

A conscientização completa-se com a Representação Memória em que a participação no grupo permite trazer à lembrança bons hábitos. Tal é o papel das Representações Sociais ao expressar simbolicamente identidades, tradições que conformam o modo de viver. Por isso, os respondentes apontam que a participação no grupo permite sempre trazer a memória de bons hábitos, que se pressupõe já sabidos ou esquecidos. Essa Representação constitui também seu próprio eixo: Memória e Antigos Saberes.

\section{CONCLUSÕES}

Analisadas as Representações Sociais identificadas durante este estudo, cabe lançar um último olhar para ressaltar aquelas cuja manifestação repetida trouxe um entendimento suplementar sobre a realidade das pessoas que elas representam: Qualidade de Vida e Prática ou Hábitos Alimentares. Sem subestimar todas as outras, pode-se dizer que essas Representações Sociais configuram o principal sistema de valor e de práticas de alimentação saudável para o grupo estudado.

Como todo trabalho, este também apresenta limitações. O próprio ineditismo do locus forçou a construção de um design de pesquisa que não pôde abarcar totalmente a comparação direta entre definições científicas de alimentação saudável e as Representações Sociais correspondentes entre os participantes do grupo. Uma futura análise temática poderá dar conta desse conteúdo.

Também é possível apontar a necessidade de expandir a pesquisa para um dos aspectos mais fascinantes das Representações Sociais: seu caráter de conhecimento com a habilidade influenciar outras pessoas. Um novo trabalho pode investigar de que maneira os participantes desse grupo influenciam outras pessoas, de fora do grupo em suas respectivas Representações, a partir da comunicação do conhecimento que é produzido pelo e no próprio grupo.

Outro ponto a merecer aprofundamento é a presença da racionalidade nutricional e a medicalização da comida nas Representações Sociais do grupo. Tema que não surgiu na análise realizada, mas de importância significativa nos debates atuais sobre alimentação saudável. A partir da apropriação do mundo exterior realizada pelas Representações Sociais, ter estudado essas Representações específicas permitiu 
conhecer melhor a construção social da realidade sobre alimentação saudável que emana da parte da sociedade representada pelo grupo pesquisado.

\section{REFERÊNCIAS}

ABRIC, J. C.. A abordagem estrutural das representações sociais. In: MOREIRA, A. S. P.; OLIVEIRA, D. C.. Estudos interdisciplinares de representação social. 2 ed. Goiânia: $A B, 2000$. p.27-37.

BAUMAN, Z.. Vida líquida. Rio de Janeiro: Jorge Zahar, 2007.

BOURDIEU, P.. A distinção: crítica social do julgamento. São Paulo: Edusp; Porto Alegre: Zouk, 2007.

CASTELLS, M. A sociedade em rede. 2 ed. São Paulo: Paz e Terra, 1999.

FONTELLES, M. J. P.; SIMÕES, M. G.; FARIAS, S. H.; FONTELLES, R. G. S.. Metodologia da pesquisa científica: diretrizes para elaboração de um protocolo de pesquisa. Revista Paraense de Medicina, Belém, v.23, p.69-76, 2009.

GIL, A. C.. Métodos e técnicas de pesquisa social. 6 ed. São Paulo: Atlas, 2008.

MOSCOVICl, S.. Representações sociais: investigações em psicologia social. Petrópolis: Vozes, 2012.
JODELET, D.. Représentations sociales: un domaine en expansion. In: JODELET, D.. Les représentations sociales. Paris: Presses Universitaires de France, 1989.

JOVCHELOVITCH, S.. Vivendo a vida com os outros: intersubjetividade, espaço público e representações sociais. In: GUARESCHI, P.; JOVCHELOVITCH, S.. Textos em representações sociais. 8 ed. Petrópolis: Vozes, 2003.

MARTINS, D. L.; DIMANTAS, H.. Por trás dos links, as pessoas. São Paulo: Le Monde Diplomatique, 2007.

OLIVEIRA, F. O.; WERBA, G. C.. Representações Sociais. In: Psicologia social contemporânea. 8 ed. Petrópolis: Vozes, 2003. p.104-117.

SILVA, M. L.; GRIMALDI, S. S. L.; FELL, A. F. A.. Tecnopólio: a rendição da cultura à tecnologia. Revista de Gestão e Tecnologia, Florianópolis, v.3, n.2, p.202-206, 2013.

VERGARA, S. C.. Projetos e relatórios de pesquisa em administração. 6 ed. São Paulo: Atlas, 2005.

ZANELLA, L. C. H.. Metodologia de estudo e de pesquisa em administração. 2 ed. Florianópolis: UFSC, 2012.

A CBPC - Companhia Brasileira de Produção Científica (CNPJ: 11.221.422/0001-03) detém os direitos materiais desta publicação. Os direitos referem-se à publicação do trabalho em qualquer parte do mundo, incluindo os direitos às renovações, expansões e disseminações da contribuição, bem como outros direitos subsidiários. Todos os trabalhos publicados eletronicamente poderão posteriormente ser publicados em coletâneas impressas sob coordenação da Cognitionis Publishing, da Companhia Brasileira de Produção Científica e seus parceiros autorizados. Os (as) autores (as) preservam os direitos autorais, mas não têm permissão para a publicação da contribuição em outro meio, impresso ou digital, em português ou em tradução. 